\title{
The Use of Catalytic Amounts of Selected Cationic Surfactants in the Design of New Synergistic Preservative Solutions
}

\author{
Paul Salama * and Ariel Gliksberg \\ Innovation Group, Sharon Laboratories Ltd., Odem St. Industrial Zone Ad-Halom, Ashdod 7898800, Israel; \\ Ariel@sharon-labs.co.il \\ * Correspondence: paul@sharon-labs.co.il; Tel.: +972-54-2166476
}

check for updates

Citation: Salama, P.; Gliksberg, A.

The Use of Catalytic Amounts of

Selected Cationic Surfactants in the Design of New Synergistic

Preservative Solutions. Cosmetics

2021, 8, 54. https://doi.org/10.3390/

cosmetics 8020054

Academic Editor: Enzo Berardesca

Received: 20 May 2021

Accepted: 11 June 2021

Published: 20 June 2021

Publisher's Note: MDPI stays neutral with regard to jurisdictional claims in published maps and institutional affiliations.

Copyright: (c) 2021 by the authors. Licensee MDPI, Basel, Switzerland. This article is an open access article distributed under the terms and conditions of the Creative Commons Attribution (CC BY) license (https:/ / creativecommons.org/licenses/by/ $4.0 /$ )

\begin{abstract}
Preservation using combinations of antibacterial molecules has several advantages, such as reducing the level of usage and broadening their antimicrobial spectrum. More specifically, the use of quaternary ammonium surfactants (QAS) — which are profusely used in hair care products and some are known as efficient antimicrobial agents-is limited due to some potential cytotoxicity concerns. This study shows that the concentration of some widely used cosmetic preservatives can be decreased when combined with very small quantities of QAS, i.e., Polyquaternium-80 (P-80) and/or Didecyldimethylammonium chloride (DDAC). The antimicrobial activity of their mixtures was first evaluated by determining the minimum inhibitory concentration (MIC) before and after the addition of QAS. Following up on this finding and targeting an ultimate consumer friendly antimicrobial blend, yet with optimal safety, we chose to utilize the food-grade preservative Maltol as the main natural origin antimicrobial agent mixed with minimum concentrations of QAS to improve its moderate antimicrobial properties. The preservatives were tested for MIC values, challenge tests and synergy using the fractional inhibitory concentration index (FICI). The antimicrobial efficacy of Maltol was found to be synergistically improved by introducing catalytic amounts of P-80 and/or DDAC.
\end{abstract}

Keywords: preservation; antimicrobial activity; quaternary ammonium surfactants; Maltol

\section{Introduction}

Surfactants are the core compounds of cosmetic formulations and contribute to a wide range of roles [1,2]. Their primary function is cleansing (mainly by anionic surfactants); however, they are also important for foaming and building product viscosity. In addition, surfactants play a key role in the performance of solubilization and deposition systems used to deliver active molecules onto the hair, scalp and skin [3].

Cationic surfactants are used for quite different purposes than the anionic surfactants, since they are not effective as anionic detergent in cleansing systems. However, they have a greater affinity for various surfaces such as skin and hair that are negatively charged [4]. Therefore, cationic surfactants are mostly found in conditioners, typically cetyltrimonium chloride or stearalkonium chloride [4]. At $\mathrm{pH}$ above the isoelectric point of hair, i.e., $\mathrm{pH} 3.67$, the cationic surfactants bind to the negative charges on the hair's keratin with their cationic heads close to the negatively charged sites on the fiber surface and their hydrophobic tail oriented away from the fiber. This results in a hydrophobic coating of the fiber, which is soft and easy to comb [5,6].

Several cationic surfactants are also acknowledged for their antimicrobial properties. They have been used as antimicrobial agents in various fields, such as food and cosmetic industries as well as hospitals [7]. Their action is generally based on their ability to disrupt the negatively charged bacterial membrane via electrostatic and hydrophobic interactions [8-11].

Preservation of cosmetic formulations is a vital task in protecting the product against contamination during manufacture, storage and use. Microbiological contamination can 
cause spoilage of cosmetic products, ultimately leading to consumers being infected by the microorganisms [12,13].

Some of the leading cationic antimicrobial surfactants are quaternary ammonium surfactants (QAS), which are amphiphilic molecules with a positively charged quaternary ammonium polar head group and one or two non-polar chains, usually n-alkyl, attached to it [14]. They can be used at a wide $\mathrm{pH}$ range which allows a great flexibility in formulations, with retention of the antimicrobial efficacy. Their microbiocidal activity has been established since the mid-1930s and during the past two decades there has been a dramatic increase in their use and their field of applications. Currently, QAS are used for various industrial purposes, including healthcare products, cleaning and disinfecting farm buildings, water and waste-water treatment, antifungal treatment in agriculture and in pharmaceutical products [15-17]. In cosmetics, QAS such as benzethonium chloride, stearalkonium chloride and cetrimonium chloride/bromide (cetrimide) have been utilized in facial cleansers, acne treatment, sun protection creams and lotions, moisturizers, hair conditioners, hair color and styling products [16,17].

The cationic charge and hydrophobic tail of the surfactants are essential factors for their antimicrobial activity but they also affect surfactants' toxicity levels [18,19]. Most traditional quaternary ammonium surfactants indiscriminately disrupt the biomembranes, regardless of cell type, showing some toxic side effects $[20,21]$. In addition, the huge consumption of surfactants worldwide has caused their build-up in the environment, which triggered the emergence of antimicrobial resistance [7,22]. Therefore, extensive efforts have been devoted to developing highly efficient antimicrobial surfactants to minimize their doses and reduce the selective stimulation to bacteria, thereby significantly lowering their toxicity $[23,24]$.

Incorporation of biocompatible groups, such as amino acids, amides or cyclodextrin, was found to reduce the cytotoxicity of cationic surfactants [7]. Combinations of natural preservatives derived from animal, plant and microbial sources is another alternative used to reduce toxicity levels [25]. Mixtures of antimicrobial molecules can potentially have additive or synergistic effects against microorganisms, hence, the concentrations needed for sufficient preservation of a cosmetic product can be lowered. Moreover, an optimal combination of preservatives could be effective against a wider spectrum of microorganisms [13].

In the current study, the susceptibility of Escherichia. coli, Staphylococcus aureus, Pseudomonas aeruginosa, Candida albicans and Aspergillus brasiliensis microorganisms to analogs of cationic surfactants was determined using MIC assay. The most effective antibacterial cationic molecules were further mixed with common cosmetic preservatives and tested at catalytic amounts to investigate whether these combinations exhibit enhanced antimicrobial properties.

To locate highly efficient antimicrobial surfactants for cosmetic uses which will be consumer friendly, we conceived new blends of preservatives containing a few beneficial QAS at catalytic amounts with the natural, food-grade preservative Maltol (2-methyl-3hydroxy-1,4-pyrone) [26]. We selected Maltol, which is found in pine needles and larch bark and has been widely used in the food industry as flavor-enhancing ingredient [27], to be incorporated in the preservative mixtures. Maltol has been listed by the Food and Drug Administration (FDA) as generally recognized as safe (GRAS) for a synthetic flavoring substance [28].

The antimicrobial properties of these blends were determined by MIC values and challenge tests. FICI was further calculated to examine the potential synergistic behavior.

\section{Materials and Methods}

Didecyldimonium Chloride (DDAC, 80\% purity) was purchased from Lonza, Morristown, NJ, USA. Dodecyltrimethylammonium chloride (>99\%), Maltol (>99\%) and Polyquaternium-2 $(63.5 \%)$ were purchased from Merck, Herzliya, Israel.Benzyldimethyldodecylammonium chloride $(>98 \%)$ and 1-Dodecyltriphenylphosphonium bromide $(>98 \%)$ were purchased from Holland Moran, Alfa Aesar, Yehud, Israel; Polyquaternium 52 (>98\%) and Polyquaternium 
55 (>99\%) from Wuhan Golden Wing Industry \& Trade, Wuhan, China; and Polyquaternium80 from Colonial Chemical, Inc., Pittsburg, TN, USA. Ethylhexylglycerin was bought from Jeevan Chemicals Pvt. Ltd., Sarigam, India; Phenoxyethanol from Tristar Intermediates Pvt. LTD, Sarigam, India; Chlorphenesin from Unilab Chemicals \& Pharmaceuticals Pvt. LTD., Maharashtra, India; and Caprylyl Glycol from Daedal Industrial Co., LTD, Seoul, Korea. Sodium Benzoate was purchased from Nantong Acetic Acid Chemical Co Ltd., Jiangsu, China and Potassium Sorbate from Wuhan Youji Industry Company Limited, Wuhan, China.

All ingredients were used without further purification.

The molecular structure of cationic surfactants used in the present work including their chemical or trade names are listed in Figure 1.

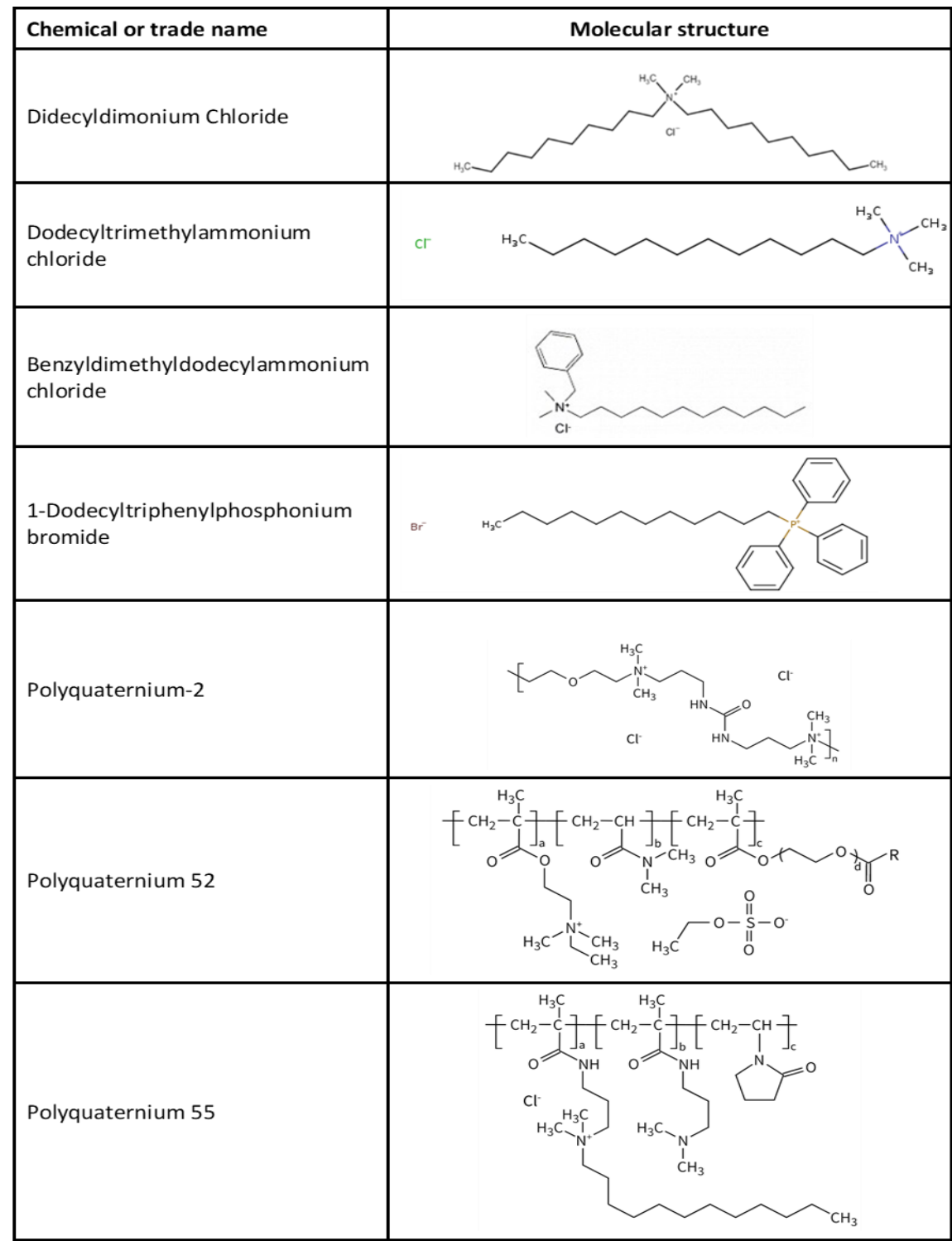

Figure 1. The chemical or trade names and molecular structure of the diverse cationic molecules studied in this work.

The following cosmetic products were used in challenge tests to evaluate the preservative abilities of selected antimicrobial blends (Figure 2). 
Nonionic basic cream

\begin{tabular}{|l|c|}
\hline Phase I & $\%$ \\
\hline Water, demineralized & Qs 100 \\
\hline Glycerin & 4.00 \\
\hline Phase II & \\
\hline Cetearyl Glucoside (and) Cetearyl Alcohol & 5.00 \\
\hline Caprylic Capric Triglycerides & 3.00 \\
\hline Cetearyl Alcohol (and) Ceteareth-20 & 4.80 \\
\hline Phase III & \\
\hline Tocopheryl acetate & 0.10 \\
\hline Phase IV & \\
\hline Preservative & \\
\hline
\end{tabular}

Rinse off anionic shampoo

\begin{tabular}{|l|c|}
\hline Phase I & $\%$ \\
\hline Water Demineralized & Qs 100 \\
\hline Glycerin & 0.30 \\
\hline Cocamidopropyl Betaine & 1.00 \\
\hline Cocamide DEA & 1.00 \\
\hline SLES 70\% & 15.00 \\
\hline Citric acid & 0.07 \\
\hline Phase II & \\
\hline Preservative & \\
\hline Phase III & \\
\hline $\mathrm{NaCl}$ & 3.50 \\
\hline
\end{tabular}

Rinse off cationic hair mask

\begin{tabular}{|l|c|}
\hline Phase I & $\%$ \\
\hline Water, demineralized & Qs 100 \\
\hline Glycerin & 3.00 \\
\hline Phase II & \\
\hline Cetearyl Glucoside (and) Cetearyl Alcohol & 2.00 \\
\hline Caprylic Capric Triglycerides & 3.00 \\
\hline Cetearyl Alcohol (and) Ceteareth-20 & 5.00 \\
\hline Behentrimonium Chloride & 1.00 \\
\hline Phase III & \\
\hline Preservative & \\
\hline
\end{tabular}

Figure 2. Formulations of three different cosmetic products that were used for challenge tests. From left to right: nonionic basic cream, rinse-off anionic shampoo and rinse-off cationic mask.

\subsection{Challenge Test}

Microorganisms' strains and growth conditions were described previously [29]. Challenge tests of preservative efficacy in formulations were performed according to ISO 11930 regulations. In order to evaluate the antimicrobial and antifungal activity of each preservative blend, samples were inoculated separately with each microorganism (Escherichia coli (ATCC 8739), Staphylococcus aureus (ATCC 6538), Pseudomonas aeruginosa (ATCC 9027), Candida albicans (ATCC 10231) and Aspergillus brasiliensis (ATCC 16404) at a final concentration of $10^{5}-10^{6} \mathrm{CFU} / \mathrm{mL}$ for bacteria and $10^{4}-10^{5}$ for yeast and mold. Samples were incubated in the dark at $22{ }^{\circ} \mathrm{C}$ for $28 \mathrm{~d}$. The preservative efficacy was determined by sampling $1 \mathrm{~g}$ from the formulation at each time point of 2, 7, 14, 21 and $28 \mathrm{~d}$. To enumerate the microorganisms at each time point, serial dilutions were made up to $10^{-4}$, and $1 \mathrm{~mL}$ were seeded onto a petri dish with the appropriate media TSA/SDA (bacteria vs. yeast respectively), using the pour plate method. Plates were incubated at $32{ }^{\circ} \mathrm{C}$ for $3 \mathrm{~d}$ for bacteria while yeast and mold were incubated at $22{ }^{\circ} \mathrm{C}$ for $5 \mathrm{~d}$ until the enumeration of viable microorganisms.

\subsection{Minimum Inhibitory Concentration (MIC)}

The minimum inhibitory concentration (MIC) for all the previously mentioned molecules were evaluated using a microdilution broth assay against the five pharmacopeia strains. Growth of E. coli, S. aureus, P. aeruginosa, C. albicans and A. brasiliensis was observed during incubation with two-fold serial dilutions of the compounds in Mueller Hinton $(\mathrm{MH})$ broth for bacteria, and Sabouraud Dextrose broth for yeast and mold, using a 96-well plate (JET BIOFIL, Be'er Sheva, Israel). The concentrations of the antimicrobial compounds ranged from up to 20,000 ppm for compounds with weaker activity, down to lower concentrations of few ppm for highly active compounds, such as DDAC. Wells were inoculated with the test cultures to give a final concentration of $5 \times 10^{5} \mathrm{CFU} / \mathrm{mL}$ of bacteria and $5 \times 10^{3} \mathrm{CFU} / \mathrm{mL}$ of yeast and mold. Bacteria inoculated plates were incubated for $24 \mathrm{~h}$ at $32{ }^{\circ} \mathrm{C}$ with shaking, while yeast and mold inoculated plates were incubated at $23^{\circ} \mathrm{C}$ for $48-72 \mathrm{~h}$ with shaking. The microorganism growth was evaluated by a spectrophotometer O.D. reads (BioTek, Bad Friedrichshall, Germany).

\section{Results and Discussion}

\subsection{The Antimicrobial Activity of Cationic Surfactants}

The antimicrobial efficacy of some analogous cationic surfactants and polymers, mainly quaternary ammonium compounds, were investigated (shown in Table 1). The chosen molecules are partially hydrophobic to allow interaction with the microbial cell membrane, however, they also possess a degree of polarity to enable their solubilization in the aqueous medium, where the microorganisms grow. The results demonstrate different antimicrobial activities for diverse molecular structures, in which DDAC exhibited the 
lowest inhibitory concentrations needed to eradicate all microorganisms' growth, similar to previous studies [30,31].

Table 1. MIC (minimum inhibitory concentration) values (expressed in ppm) of cationic surfactants against Escherichia. coli, Staphylococcus aureus, Pseudomonas aeruginosa, Candida albicans and Aspergillus brasiliensis microorganisms.

\begin{tabular}{cccccc}
\hline Preservative & E. coli & S. aureus & P. aeruginosa & C. albicans & A. brasiliensis \\
\hline $\begin{array}{c}\text { Didecyldimethylammonium } \\
\text { chloride (DDAC) }\end{array}$ & 2 & 0.5 & 15 & 3 & 7 \\
\hline $\begin{array}{c}\text { Dodecyltrimethylammonium } \\
\text { chloride }\end{array}$ & 45 & 20 & 360 & 45 & 360 \\
\hline $\begin{array}{c}\text { Benzyldimethyldodecylammonium } \\
\text { chloride }\end{array}$ & 45 & 15 & 120 & 20 & $<60$ \\
\hline $\begin{array}{c}\text { 1-Dodecyltriphenylphophonium } \\
\text { bromide }\end{array}$ & $<200$ & $<200$ & $<200$ & $<200$ & $<200$ \\
\hline Polyquaternium-2 & 15 & 7.5 & 60 & 45 & 2000 \\
\hline Polyquaternium-52 & $>2000$ & $>2000$ & $>2000$ & 900 & $>3000$ \\
\hline Polyquaternium-55 & $>600$ & $>600$ & $>600$ & $>1200$ & $>1200$ \\
\hline Polyquaternium-80 & 360 & 120 & $>600$ & 240 & 120 \\
\hline
\end{tabular}

The antimicrobial activity can be affected by the chemical structure, mainly the number and length of hydrophobic chains, position and number of cationic charges and the polar head structure. Increasing the cationic charge and hydrophobicity is known to improve antimicrobial properties of cationic surfactants [25].

When examining the cationic ammonium surfactants (having one cationic site), the activity was found to be as follows: Didecyldimethylammonium chloride (DDAC) > Benzyldimethyldodecylammonium chloride $($ BDAC) $>$ Dodecyltrimethylammonium chloride. These results emphasize that hydrophobic interactions are necessary for antimicrobial activity; therefore, DDAC, having two decyl chains $\left(2 \times \mathrm{C}_{10}\right)$, was more efficient than Dodecyltrimethylammonium chloride with one dodecyl tail $\left(1 \times \mathrm{C}_{12}\right)$.

Furthermore, 1-Dodecyltriphenylphophonium bromide, which has three phenyl groups in addition to a different cationic site and phosphonium instead of ammonium, exhibited lower antimicrobial activity.

The hydrophobic part of antimicrobial agents has been previously identified as a key role in disrupting the cell membrane, which leads to the death of bacteria [25]. It is reasonable to assume that the tested alkyls chains, with carbon length of 8-12, would be more effective in perturbating the microbes' cell wall than multiple bulky groups as phenyls.

The impact of antimicrobial lipophilicity and number of cationic sites was observed by testing various polyquaternium. Polyquaternium-2 possesses two quaternary ammonium sites per monomer unit and demonstrated the highest antimicrobial activity among the tested polymers.

Polyquaternium-52 and Polyquaternium-55 with one quaternary ammonium group per monomer unit and longer alkyl chain, i.e., C18, were significantly less effective. It is well known that the activity of quaternary ammonium molecules is an approximate parabolic function of the compound's lipophilicity (alkyl chain length), which is maximized with chain lengths of 10-16 carbons [16].

The naturally derived Polyquaternium- 80 with one cationic site and two alkyl chains $\left(C_{10}, C_{8}\right)$ was relatively highly active against the tested organisms.

\subsection{Cationic Surfactants as Antimicrobial Catalysts}

To design a preservative agent with a broader spectrum of activity and improved safety, quaternary ammonium mixtures were further blended with additional common preservatives. 
The two leading QAS, DDAC and BDAC, were tested at low doses to examine their catalytic antimicrobial abilities with known preservative blends, made for example of Ethylhexylglycerin (EHG) and Phenoxyethanol [32].

The MIC values of EHG/Phenoxyethanol (14/86 wt/wt ratio) were 3000-4000 ppm (Table 2). Introducing $5 \mathrm{wt} \%$ of BDAC or DDAC to the expense of Phenoxyethanol significantly reduced MIC values to 100-800 and 100-200 ppm, respectively. The addition of either cationic surfactant drastically improved the antimicrobial activity of the mixture. Once more, DDAC displayed higher preservative abilities than BDAC.

Table 2. MIC values (expressed in ppm) of Ethylhexylglycerin and Phenoxyethanol mixture and with addition of 5\% Benzyldimethyldodecylammonium chloride or 5\% Didecyldimethylammonium chloride cationic surfactants.

\begin{tabular}{cccccc}
\hline Preservative & E. coli & S. aureus & P. aeruginosa & C. albicans & A. brasiliensis \\
\hline $\begin{array}{c}14 \% \text { Ethylhexylglycerin } \\
86 \% \text { Phenoxyethanol }\end{array}$ & 4000 & 4000 & 4000 & 4000 & 3000 \\
\hline $\begin{array}{c}14 \% \text { Ethylhexylglycerin } \\
81 \% \text { Phenoxyethanol }\end{array}$ & 400 & 100 & 800 & 100 & 100 \\
$\begin{array}{c}5 \% \text { Benzyldimethyldodecylammonium } \\
\text { chloride }\end{array}$ & 100 & 200 & 200 & 100 & 100 \\
\hline $\begin{array}{c}14 \% \text { Ethylhexylglycerin } \\
81 \% \text { Phenoxyethanol } \\
5 \% \text { Didecyldimethylammonium } \\
\text { chloride }\end{array}$ & & & &
\end{tabular}

The MIC values of additional common combinations of preservative blends were determined, in the absence and presence of DDAC (Table 3). The blend composed of Phenoxyethanol 85\%, Chlorphenesin 10\% and Caprylyl Glycol 5\% showed relatively good antimicrobial activity. Replacing $5 \%$ of Phenoxyethanol by DDAC led to a drastic enhancement of the antimicrobial abilities against all microorganisms.

Table 3. MIC values (expressed in ppm) of $85 \%$ Phenoxyethanol, 10\% Chlorphenesin, 5\% Caprylyl Glycol mixture; and 80\% Phenoxyethanol, 10\% Chlorphenesin, 5\% Caprylyl Glycol and 5\% DDAC.

\begin{tabular}{|c|c|c|c|c|c|}
\hline Preservative & E. coli & S. aureus & P. aeruginosa & C. albicans & A.brasiliensis \\
\hline $\begin{array}{c}85 \% \text { Phenoxyethanol, } 10 \% \\
\text { Chlorphenesin, } 5 \% \text { Caprylyl Glycol } \\
\text { mixture }\end{array}$ & $>1000$ & $>1000$ & $>1000$ & $>1000$ & $>1000$ \\
\hline $\begin{array}{c}80 \% \text { Phenoxyethanol, } 10 \% \\
\text { Chlorphenesin, } 5 \% \text { Caprylyl Glycol } \\
\text { mixture and 5\% DDAC }\end{array}$ & 62 & 4 & 250 & 62 & 125 \\
\hline
\end{tabular}

Similarly, the preservative ability of a mixture comprised of $29 \%$ Sodium Benzoate, 14\% Potassium Sorbate and 57\% water were limited especially against $P$. aeruginosa and A. brasiliensis (Table 4). However, the addition of only $2.5 \%$ DDAC (on the expense of water) was sufficient to reduce the minimum inhibitory concentration by $1-2$ order of magnitude.

Table 4. MIC values (expressed in ppm) of 54.5\% Water, 29\% Sodium Benzoate, $14 \%$ Potassium Sorbate; and of 52\% Water, $29 \%$ Sodium Benzoate, $14 \%$ Potassium Sorbate with addition of $2.5 \%$ Didecyldimethylammonium chloride cationic surfactants.

\begin{tabular}{cccccc}
\hline Preservative & E. coli & S. aureus & P. aeruginosa & C. albicans & A. brasiliensis \\
\hline $\begin{array}{c}57 \% \text { Water, 29\% Sodium Benzoate, 14\% } \\
\text { Potassium Sorbate }\end{array}$ & 7000 & 4000 & 13,000 & 4000 & 2500 \\
\hline $\begin{array}{c}54.5 \% \text { Water, 29\% Sodium Benzoate, 14\% } \\
\text { Potassium Sorbate and 2.5\% DDAC }\end{array}$ & 100 & 50 & 300 & 75 & 150 \\
\hline
\end{tabular}


The concentrations needed for sufficient preservation of the different mixtures, measured by MIC, were decreased due to the highly efficient antimicrobial activity of DDAC, thereby alleviating its toxicity concerns.

To widen the use of cationic surfactants in preservative solutions, the antimicrobial ability of DDAC and P-80 in the presence of ingredients that are known in the preservative field, not as antimicrobials but as additives, was further evaluated. Commonly used as co-solvent, 2-Methyl-1,3-propanediol was combined with the preservative catalyst, Caprylyl glycol, and their antimicrobial activity was examined using MIC assay (Table 5). As anticipated, the 'phenoxyethanol-free' combination (2-Methyl-1,3-propanediol and Caprylyl glycol) has a very low preservative ability prior to the addition of DDAC and P-80, mainly against C. albicans and P. aeruginosa. However, once 10\% P-80 and 2.5\% DDAC were added to the blend, the antimicrobial activity was drastically increased. For example, in the case of C. albicans and P. aeruginosa, upon addition of DDAC and P-80, the minimum inhibitory concentration values decreased from 20,000 and 10,000 ppm to 800 and 2000 ppm, respectively.

Table 5. MIC values (expressed in ppm) of 2-Methyl-1,3-Propanediol 40\%, Caprylyl Glycol 25\%, Water 35\%; and 2-Methyl-1,3-Propanediol 40\%, Caprylyl Glycol 25\%, Water 22.5\%, Polyquaternium80 10\%, Didecyldimethylammonium chloride (DDAC) 2.5\% mixtures.

\begin{tabular}{cccccc}
\hline Preservative & E. coli & S. aureus & P. aeruginosa & C. albicans & A. brasiliensis \\
\hline $\begin{array}{c}40 \% \text { 2-Methyl-1,3-propanediol, 25\% } \\
\text { Caprylyl Glycol, 35\% Water }\end{array}$ & 5000 & 5000 & 10,000 & 20,000 & 5000 \\
\hline $\begin{array}{c}40 \% \text { 2-Methyl-1,3-propanediol, 25\% } \\
\text { Caprylyl Glycol, 22.5\% Water, 10\% } \\
\text { Polyquaternium-80 and 2.5\% DDAC }\end{array}$ & 1600 & 200 & 2000 & 800 & 200 \\
\hline
\end{tabular}

\subsection{Maltol/QAS Nature-Based Preservatives}

The natural substance Maltol was previously reported to exhibit antimicrobial activity against Bacillus subtilis, S. aureus, Staphylococcus epidermidis, E. coli, P. aeruginosa, Klebsiella pneumoniae, A. brasiliensis, Aspergillus flavus, C. albicans and Saccharomyces cerevisiae [33].

In this study, we aimed to utilize Maltol's advantages as a naturally occurring antimicrobial, with a wide window of $\mathrm{pH}$ efficacy and water solubility, as a natural basis for conceiving highly efficient, consumer friendly preservative blends [34].

The minimum inhibitory concentration of Maltol was tested (Figure 3) and demonstrated its antimicrobial activity against E. coli, S. aureus, P. aeruginosa, C. albicans and A. brasiliensis.

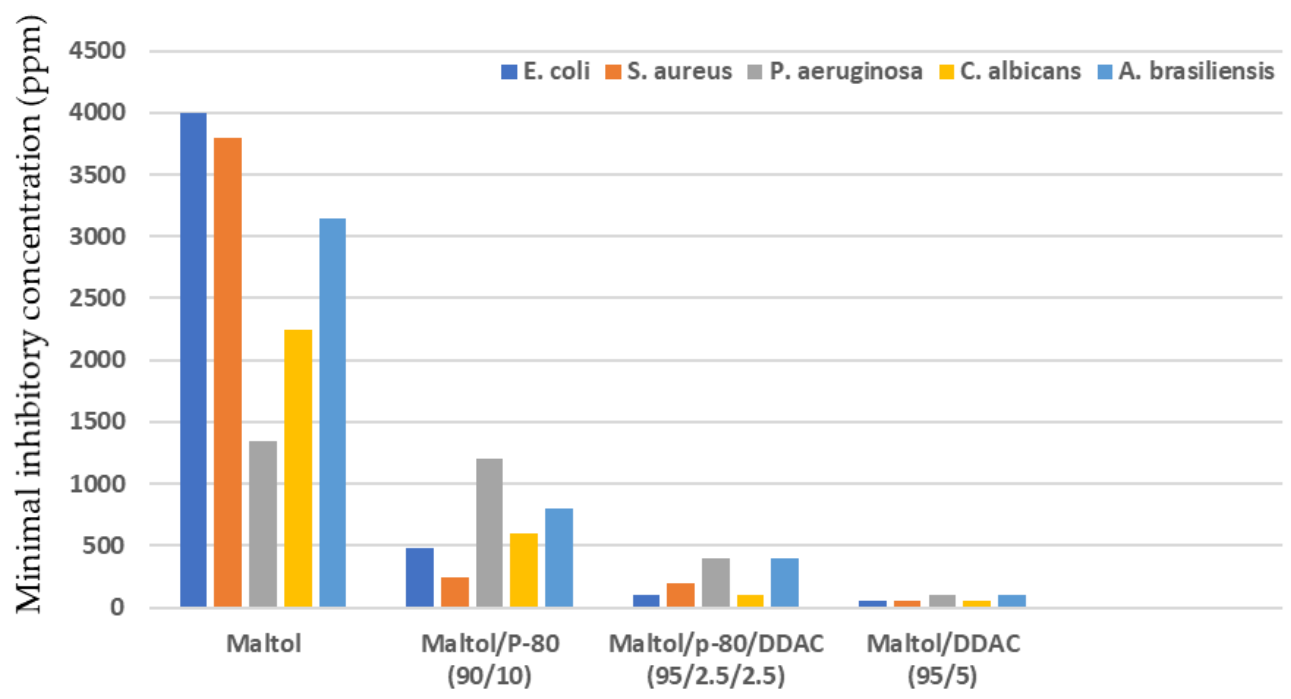

Figure 3. MIC values (ppm) of Maltol, Maltol/P-80 (90/10), Maltol/P-80/DDAC (95/2.5/2.5) and Maltol/DDAC (95/5). 
To develop ideal natural-based preservatives, their usage concentrations should be as low as possible in order to minimize their interference with the final product performance. To achieve this goal, Maltol was combined with catalytic amounts of cationic surfactants, i.e., P-80, which is a naturally derived compound, and/or DDAC to enhance its efficiency.

The results presented in Figure 3 indicate that incorporation of either $10 \% \mathrm{P}-80,5 \% \mathrm{P}-$ 80/DDAC $1 / 1$ or 5\% DDAC significantly improved Maltol's antimicrobial activity. The nature-based mixture of Maltol/P-80 (9/1) showed good antimicrobial activity, while introducing DDAC further enhanced the antimicrobial properties. It is reasonable to conclude that P-80 or DDAC enhanced Maltol's antimicrobial activity by introducing electrostatic and hydrophobic interactions, while Maltol hydrogen bonds and chelation abilities would further contribute targeting and interacting with the bacterial surface. As a result, the Maltol/QAS mixtures possess amplified antimicrobial abilities.

The tested Maltol/QAS mixtures demonstrated a particularly strong activity against the microorganisms' growth, even when compared to the commonly used preservatives that are not natural originated. Their minimal inhibitory concentration values were 100-400 and 50-100 ppm for Maltol/P-80/DDAC and Maltol/DDAC mixtures, respectively.

\subsection{Challenge Tests}

It is difficult to accurately predict the effectiveness of a preservative in the final product. A challenge test is a procedure in which a product is challenged by exposure to specified types of microbes to determine whether it is adequately preserved. It is required both for the selection of preservative molecules for new formulations and to establish that manufactured products are effectively preserved during storage and use, i.e., for stability testing.

Both the European Pharmacopoeia (EP) and the United States Pharmacopoeia (USP) [33] recommend (i) a Gram-positive coccus, Staphylococcus aureus, (ii) a Gram-negative rod, Pseudomonas aeruginosa and Escherichia coli, (iii) a mold, Aspergillus brasiliensis and (iv) a yeast, Candida albicans [35]. Since USP is less strict, we followed EP acceptance criteria. The preservative properties are considered adequate when there is 100-fold and 1000-fold reduction from the initial bacteria inoculated count at days 2 and 7, respectively. Moreover, no increase in bacterial count should appear from day 14 to day 28 [17,25,36]. Yeast and mold must show $2 \log$ reduction after $14 \mathrm{~d}$ with no further increase in the following weeks $[17,25,36]$.

The known antimicrobial substances, EHG and Phenoxyethanol, that were empowered upon the addition of DDAC and exhibited reduced MIC values (Table 2), were further evaluated by challenge tests.

The susceptibility of the microorganisms to $0.5 \%$ of EHG/Phenoxyethanol/DDAC blend in three different cosmetic formulations-anionic surfactant-based shampoo, cationic surfactants-based hair mask and nonionic surfactants-based cream-is shown in Table 6. The formulation description of each cosmetic product is shown in Figure 2.

The challenge tests' results showed that the cosmetic formulations containing either cationic or nonionic surfactants passed the EP test criteria which is in accordance with the detected, relatively low MIC values. However, when using the anionic-based cosmetic formulation, the reduction of $E$. coli inoculated count was not adequate to meet the test criteria.

At this point, it could be invoked that the inherent differences between the typical formulations used-i.e., the basic cream and the cationic rinse-off (hair mask) are emulsion systems, while the anionic rinse-off (shampoo) is a mono-phasic aqueous medium-are involved in the above mentioned difference of performance. Noteworthy is the fact that the shampoo formulation, being rich in sulfate anionic species (SLES), could potentially interact with the preservative system's cationic nature. (This phenomenon is further investigated and will be fully addressed in a following article.) 
Table 6. Challenge test of classical preservative mixture (0.5\%) composed of Ethylhexylglycerin and Phenoxyethanol (14/81) with addition of $5 \%$ Didecyldimethylammonium chloride in three different cosmetic formulations: shampoo (based on anionic surfactants), hair mask (cationic) and basic cream (nonionic) as described in Figure 2.

\begin{tabular}{|c|c|c|c|c|c|c|}
\hline $\begin{array}{c}\text { Cosmetic Product } \\
\text { Preservative Level } \\
\text { of Use } 0.5 \%\end{array}$ & $\begin{array}{c}\text { Time of Reading } \\
\text { (days) }\end{array}$ & E. coli $(\mathrm{cfu} / \mathrm{mL})$ & S. aureus $(\mathrm{cfu} / \mathrm{mL})$ & $\begin{array}{l}\text { P. aeruginosa } \\
(\mathrm{cfu} / \mathrm{mL})\end{array}$ & $\begin{array}{l}\text { C. albicans } \\
(\mathrm{cfu} / \mathrm{mL})\end{array}$ & $\begin{array}{l}\text { A. brasiliensis } \\
(\mathrm{cfu} / \mathrm{mL})\end{array}$ \\
\hline \multirow{6}{*}{ Shampoo-Anionic } & Inoculum & $1.1 \times 10^{6}$ & $1 \times 10^{6}$ & $1.1 \times 10^{6}$ & $1 \times 10^{5}$ & $1.1 \times 10^{5}$ \\
\hline & 2 & $2 \times 10^{5}$ & $8.5 \times 10^{2}$ & $<10$ & $1 \times 10^{5}$ & $1.1 \times 10^{3}$ \\
\hline & 7 & $2 \times 10^{5}$ & $<10$ & $<10$ & $1.8 \times 10^{3}$ & $1.2 \times 10^{3}$ \\
\hline & 14 & $2 \times 10^{5}$ & $<10$ & $<10$ & $2.5 \times 10^{2}$ & $1 \times 10^{3}$ \\
\hline & 21 & $2 \times 10^{5}$ & $<10$ & $<10$ & $<10$ & $8.5 \times 10^{2}$ \\
\hline & 28 & $2.6 \times 10^{5}$ & $<10$ & $<10$ & $<10$ & $6.6 \times 10^{2}$ \\
\hline \multirow{6}{*}{ mask-Cationic } & Inoculum & $1 \times 10^{6}$ & $1 \times 10^{6}$ & $1 \times 10^{6}$ & $1 \times 10^{5}$ & $1 \times 10^{5}$ \\
\hline & 2 & $2 \times 10^{1}$ & $3.8 \times 10^{3}$ & $8 \times 10^{3}$ & $<10$ & $4 \times 10^{4}$ \\
\hline & 7 & $<10$ & $1 \times 10^{1}$ & $<10$ & $<10$ & $5 \times 10^{3}$ \\
\hline & 14 & $<10$ & $<10$ & $<10$ & $<10$ & $2 \times 10^{3}$ \\
\hline & 21 & $<10$ & $<10$ & $<10$ & $<10$ & $1 \times 10^{3}$ \\
\hline & 28 & $<10$ & $<10$ & $<10$ & $<10$ & $1 \times 10^{3}$ \\
\hline \multirow{6}{*}{$\begin{array}{c}\text { Basic } \\
\text { cream-Nonionic }\end{array}$} & Inoculum & $1 \times 10^{6}$ & $1 \times 10^{6}$ & $1 \times 10^{6}$ & $1 \times 10^{5}$ & $1 \times 10^{5}$ \\
\hline & 2 & $4 \times 10^{4}$ & $<10$ & $6.6 \times 10^{3}$ & $5.5 \times 10^{2}$ & $3.1 \times 10^{4}$ \\
\hline & 7 & $<10$ & $<10$ & $<10$ & $<10$ & $8.5 \times 10^{3}$ \\
\hline & 14 & $<10$ & $<10$ & $<10$ & $<10$ & $2 \times 10^{3}$ \\
\hline & 21 & $<10$ & $<10$ & $<10$ & $<10$ & $1 \times 10^{3}$ \\
\hline & 28 & $<10$ & $<10$ & $<10$ & $<10$ & $1 \times 10^{3}$ \\
\hline
\end{tabular}

The susceptibility of E. coli, S. aureus, P. aeruginosa, C. albicans and A. brasiliensis microorganisms to Maltol/QAS blends was evaluated by challenge tests (Table 7). The three combinations of Maltol/QAS were used at a low level of $0.5 \%$ of the total finished cosmetic product of nonionic surfactant-based cream (see description in Figure 2).

Table 7. Challenge tests of $0.5 \%$ natural origin preservative mixtures composed of Maltol/P-80 90/10, Maltol/P-80/DDAC 95/2.5/2.5 and Maltol/DDAC 95/5 in basic cream cosmetic formulation (based on nonionic surfactants), as described in Figure 2.

\begin{tabular}{|c|c|c|c|c|c|c|}
\hline $\begin{array}{c}\text { Preservative Level of } \\
\text { Use } 0.5 \%\end{array}$ & $\begin{array}{c}\text { Time of Reading } \\
\text { (days) }\end{array}$ & $\begin{array}{c}\text { E. coli } \\
(\mathrm{cfu} / \mathrm{mL})\end{array}$ & $\begin{array}{l}\text { S. aureus } \\
(\mathrm{cfu} / \mathrm{mL})\end{array}$ & $\begin{array}{l}\text { P. aeruginosa } \\
(\mathrm{cfu} / \mathrm{mL})\end{array}$ & $\begin{array}{l}\text { C. albicans } \\
\text { (cfu/mL) }\end{array}$ & $\begin{array}{l}\text { A. brasiliensis } \\
\text { (cfu/mL) }\end{array}$ \\
\hline \multirow{6}{*}{ Maltol/P-80 (90/10) } & Inoculum & $1.1 \times 10^{6}$ & $1 \times 10^{6}$ & $1.1 \times 10^{6}$ & $1.1 \times 10^{5}$ & $1 \times 10^{5}$ \\
\hline & 2 & $<10$ & $<10$ & $<10$ & $<10$ & $4.3 \times 10^{4}$ \\
\hline & 7 & $<10$ & $<10$ & $<10$ & $<10$ & $6.7 \times 10^{3}$ \\
\hline & 14 & $<10$ & $<10$ & $<10$ & $<10$ & $3 \times 10^{1}$ \\
\hline & 21 & $<10$ & $<10$ & $<10$ & $<10$ & $2 \times 10^{1}$ \\
\hline & 28 & $<10$ & $<10$ & $<10$ & $<10$ & $<10$ \\
\hline \multirow{6}{*}{$\begin{array}{c}\text { Maltol/P-80/DDAC } \\
(95 / 2.5 / 2.5)\end{array}$} & Inoculum & $1 \times 10^{6}$ & $1 \times 10^{6}$ & $1 \times 10^{6}$ & $1 \times 10^{5}$ & $1 \times 10^{5}$ \\
\hline & 2 & $<10$ & $<10$ & $<10$ & $<10$ & $<10$ \\
\hline & 7 & $<10$ & $<10$ & $<10$ & $<10$ & $<10$ \\
\hline & 14 & $<10$ & $<10$ & $<10$ & $<10$ & $<10$ \\
\hline & 21 & $<10$ & $<10$ & $<10$ & $<10$ & $<10$ \\
\hline & 28 & $<10$ & $<10$ & $<10$ & $<10$ & $<10$ \\
\hline \multirow{6}{*}{ Maltol/DDAC (95/5) } & Inoculum & $1 \times 10^{6}$ & $1 \times 10^{6}$ & $1 \times 10^{6}$ & $1 \times 10^{5}$ & $1 \times 10^{5}$ \\
\hline & 2 & $<10$ & $<10$ & $<10$ & $1.7 \times 10^{3}$ & $3 \times 10^{4}$ \\
\hline & 7 & $<10$ & $<10$ & $<10$ & $<10$ & $7.2 \times 10^{3}$ \\
\hline & 14 & $<10$ & $<10$ & $<10$ & $<10$ & $3 \times 10^{2}$ \\
\hline & 21 & $<10$ & $<10$ & $<10$ & $<10$ & $2 \times 10^{1}$ \\
\hline & 28 & $<10$ & $<10$ & $<10$ & $<10$ & $<10$ \\
\hline
\end{tabular}

The challenge tests' results demonstrated that all cosmetic formulations, containing different preservative combinations, passed the EP test criteria which is in accordance with the detected relatively low MIC values.

Even at low levels of natural origin preservative, incorporation of either $0.05 \% \mathrm{P}$ $80,0.025 \%$ P-80/DDAC $1 / 1$ or $0.025 \%$ DDAC (of the total product)-i.e., 500, 250 and 250 ppm-significantly improved Maltol's antimicrobial activity in the final product. The nature-based mixture of Maltol/P-80 (9/1) showed excellent preservative properties, while 
the addition of DDAC further enhanced the antimicrobial properties, especially against A. brasiliensis. We concluded that even minimal concentrations of P-80 and/or DDAC in conjunction with Maltol were still adequately preserving the cosmetic formulation and complied with the EP criteria.

\subsection{Synergistic Effect}

Measuring synergy between preservatives can be realized by the widely described Fractional Inhibitory Concentration Index (FICI) [37,38].

While the MIC is defined as the lowest concentration of molecule alone or in combination that inhibited visible growth, the in vitro interactions can be quantified as FICI and calculated using the following formula:

$$
\text { FICI }=\frac{\text { MIC of compound } A_{\text {combined }}}{\text { MIC of compound } A_{\text {alone }}}+\frac{\text { MIC of compound } B_{\text {combined }}}{\text { MIC of compound } B_{\text {alone }}}
$$

FICI values were interpreted as follows: <0.5 synergy, 0.5-0.75 partial synergy, $0.75-1.0$ additive effect, $1.0-4.0$ no interaction and a FICI of $>4.0$ was defined as antagonism [38].

The combined use of Maltol and QAS against all microorganisms resulted in a FICI of 0.05-1.75 (Table 8). None of the blends exhibited an antagonistic effect (FICI > 4.0).

Table 8. FICI values for the three blends: Maltol/P-80 (90/10), Maltol/P-80/DDAC (95/2.5/2.5) and Maltol/DDAC (95/5) based on the MIC results presented in Table 1 and Figure 3.

\begin{tabular}{cccccc}
\hline Preservative (ppm) & E. coli & S. aureus & P. aeruginosa & C. albicans & A. brasiliensis \\
\hline Maltol/P-80 (90/10) & 0.32 & 0.26 & 0.77 & 0.67 & 0.33 \\
\hline $\begin{array}{c}\text { Maltol/P-80/DDAC } \\
(95 / 2.5 / 2.5)\end{array}$ & 1.76 & 0.86 & 0.97 & 0.54 & 0.14 \\
\hline Maltol/DDAC (95/5) & 0.37 & 0.76 & 0.73 & 0.04 & 0.05 \\
\hline
\end{tabular}

Mixing Maltol with P-80 synergistically reduced all microorganisms' levels. Higher synergism was displayed against E. coli, S. aureus and A.brasiliensis. The ternary mixture of Maltol/P-80/DDAC had good activity against all the microorganisms; however, synergy was detected only against mold and yeast (A. brasiliensis and C. albicans). The Maltol and DDAC blend revealed the lowest FICI values which interpreted as the most synergetic interaction in the current study. Extremely high synergy levels were observed against mold and yeast (A. brasiliensis and C. albicans) with minimal FICI values of $0.04-0.05$. In addition, a good synergy was seen against $E$. coli.

FICI values confirmed that combining Maltol with the current cationic quaternary surfactants can be used at lower levels to sufficiently suppress microbe growth, since the mild antimicrobial activity of Maltol is intensified by the addition of P-80 and/or DDAC.

\section{Tentative Mode of Action and Conclusions}

Membranes are primarily composed of proteins, embedded within a lipid matrix. Many of these membrane proteins are required for maintaining the membrane's structural integrity, while others are needed for more functional tasks [25].

Each protein is surrounded by phospholipids that interact with the protein, thereby moderating the protein's functionality. The outermost surface of the bacterial cells generally carries a net negative charge, which is often stabilized by the presence of divalent cations such as $\mathrm{Mg}^{2+}$ and $\mathrm{Ca}^{2+}$.

DDAC or P-80 cationic antimicrobials are considered to initially interact with the microorganism's cell wall by displacing these divalent cations. Maltol is assumed to act as a chelator that can perturb membrane structure through the sequestration of stabilizing metal cations [16]. 
Further interactions of the cationic surfactants with the lipid bilayer are known to depend on the specific nature of the antimicrobial molecule, mainly the length of the n-alkyl chain [16].

We conclude that the combined preservative molecules can therefore disrupt the membrane, thus increasing its fluidity and allowing the release of vital intracellular elements, leading to the microbe's cell death.

Combinations of typical and widely used conventional preservatives and compounds with antimicrobial activity, EHG/Phenoxyethanol, Phenoxyethanol/Chlorphenesin/Caprylyl Glycol and Sodium Benzoate/ Potassium Sorbate, were less effective in MIC assay when compared with minimal additional concentrations of DDAC and/or P-80 (e.g., 250-500 ppm of a final product).

Efficacious antimicrobial protection was demonstrated mainly for the natural origin Maltol/QAS combinations based on MIC and challenge results. FICI calculations revealed a synergetic effect due to the incorporation of catalytic amounts of P-80 and/or DDAC.

Taken together, we conclude that catalytic quantities of specially selected QAS were sufficient to create novel, synergistic, natural-based preservative blends displaying high antimicrobial efficacy, while maintaining a low level of use in the finished cosmetic product.

Author Contributions: Conceptualization, P.S.; methodology, P.S. and A.G.; validation, P.S. and A.G.; formal analysis, A.G.; investigation, P.S.; data curation, A.G.; writing-original draft preparation, P.S.; writing-review and editing, P.S.; supervision, P.S.; project administration, P.S.; funding acquisition, P.S. All authors have read and agreed to the published version of the manuscript.

Funding: This research was funded by Israel Innovation Authority, grant number 67311.

Institutional Review Board Statement: Not applicable.

Informed Consent Statement: Not applicable.

Data Availability Statement: Not applicable.

Acknowledgments: We thank Inbal Tzafrir for her contribution in administration, Idit Yuli for her contribution in the paper editing and the fruitful discussions and Noa Ziklo for her final review.

Conflicts of Interest: The authors declare no conflict of interest.

\section{References}

1. Donaldson, B.R.; Messenger, E.T. Performance characteristics and solution properties of surfactants in shampoos. Int. J. Cosmet. Sci. 1979, 1, 71-90. [CrossRef] [PubMed]

2. Arif, S. The formulation basics for personal cleansers. HAPPI 2009, 46, 73-75.

3. Cornwell, P.A. A review of shampoo surfactant technology: Consumer benefits, raw materials and recent developments. Int. J. Cosmet. Sci. 2018, 40, 16-30. [CrossRef]

4. Reich, C. Surfactants in Cosmetics, Surfactant Science Series; Rieger, M.M., Rhein, L.D., Eds.; Marcel Dekker: New York, NY, USA, 1997; Volume 68, Chapter 16, p. 357.

5. Forster, T.; Schwuger, M.J. Correlation Between Adsorption and the Effects of Surfactants and Polymers on Hair. Prog. Colloid Polym. Sci. 1990, 83, 104-109.

6. Rhein, L. Handbook for Cleaning/Decontamination of Surfaces; Johansson, I., Somasundaran, P., Eds.; Elsevier B.V.: Alpharetta, GA, USA, 2007; Volume 1, Chapter 3, p. 305.

7. Zhou, C.; Wang, Y. Structure-Activity Relationship of Cationic Surfactants as Antimicrobial Agents. Curr. Opin. Colloid Interface Sci. 2020, 45, 28-43. [CrossRef]

8. McDonnell, G.; Russell, A.D. Antiseptics and disinfectants: Activity, action, and resistance. Clin. Microbiol. Rev. 1999, 12, 147-179. [CrossRef]

9. Aiad, I.L.; Badawi, A.M.; El-Sukkary, M.M.; El-Sawy, A.A.; Adawy, A.I. Synthesis and Biocidal Activity of Some NaphthaleneBased Cationic Surfactants. J. Surfact. Deterg. 2012, 15, 223-234. [CrossRef]

10. Hoque, J.; Akkapeddi, P.; Yarlagadda, V.; Uppu, D.S.; Kumar, P.; Haldar, J. Cleavable cationic antibacterial amphiphiles: Synthesis, mechanism of action, and cytotoxicities. Langmuir 2012, 28, 12225-12234. [CrossRef] [PubMed]

11. Hoque, J.; Konai, M.M.; Samaddar, S.; Gonuguntala, S.; Manjunath, G.B.; Ghosh, C.; Haldar, J. Selective and broad spectrum amphiphilic small molecules to combat bacterial resistance and eradicate biofilms. Chem. Commun. 2015, 51, 13670-13673. [CrossRef] [PubMed] 
12. Alvarez-Lerma, F.; Maull, E.; Terradas, R.; Sequra, C.; Planells, I.; Coll, P.; Knobel, H.; Vázquez, A. Moisturizing body milk as a reservoir of Burkholderia cepacia: Outbreak of nosocomial infection in a multidisciplinary intensive care unit. Crit. Care 2008, 12, R10. [CrossRef] [PubMed]

13. Lundov, M.D.; Johansen, J.D.; Zachariae, C.; Moesby, L. Low-level efficacy of cosmetic preservatives. Int. J. Cosmet. Sci. 2011, 33, 190-196. [CrossRef]

14. Inácio, A.S.; Domingues, N.S.; Nunes, A.; Martins, P.T.; Moreno, M.J.; Estronca, L.M.; Fernandes, R.; Moreno, A.J.M.; Borrego, M.J.; Gomes, J.P.; et al. Quaternary ammonium surfactant structure determines selective toxicity towards bacteria: Mechanisms of action and clinical implications in antibacterial prophylaxis. J. Antimicrob. Chemother. 2016, 71, 641-654. [CrossRef]

15. Walker, E.B. Handbook of Topical Antimicrobials: Industrial Applications in Consumer Products and Pharmaceuticals; Paulson, D., Ed.; Marcel Dekker: New York, NY, USA, 2003; Chapter 5, p. 99.

16. Gilbert, P.; Moore, L.E. Cationic antiseptics: Diversity of action under a common epithet. J. Appl. Microbiol. 2005, 99, 703-715. [CrossRef]

17. Buffet-Bataillon, S.; Tattevin, P.; Bonnaure-Mallet, M.; Jolivet-Gougeon, A. Emergence of resistance to antibacterial agents: The role of quaternary ammonium compounds-A critical review. Int. J. Antimicrob. Agents 2012, 39, 381-389. [CrossRef] [PubMed]

18. Colomer, A.; Pinazo, A.; Manresa, M.A.; Vinardell, M.P.; Mitjans, M.; Infante, M.R.; Pérez, L. Cationic surfactants derived from lysine: Effects of their structure and charge type on antimicrobial and hemolytic activities. J. Med. Chem. 2011, 54, 989-1002. [CrossRef]

19. Manaargadoo-Catin, M.; Ali-Cherif, A.; Pougnas, J.-L.; Perrin, C. Hemolysis by surfactants-A review. Adv. Colloid Interface Sci. 2016, 228, 1-16. [CrossRef]

20. Zhang, S.; Ding, S.; Yu, J.; Chen, X.; Lei, Q.; Fang, W. Antibacterial activity, in vitro cytotoxicity and cell cycle arrest of gemini quaternary ammonium surfactants. Langmuir 2015, 31, 12161-12169. [CrossRef] [PubMed]

21. Lukáč, M.; Mojžiš, J.; Mojžišová, G.; Mrva, M.; Ondriska, F.; Valentová, J.; Lacko, I.; Bukovský, M.; Devínsky, F.; Karlovská, J. Dialkylamino and nitrogen heterocyclic analogues of hexadecylphosphocholine and cetyltrimetylammonium bromide: Effect of phosphate group and environment of the ammonium cation on their biological activity. Eur. J. Med. Chem. 2009, 44, 4970-4977. [CrossRef]

22. Jennings, M.C.; Minbiole, K.P.; Wuest, W.M. Quaternary ammonium compounds: An antimicrobial mainstay and platform for innovation to address bacterial resistance. ACS Infect. Dis. 2015, 1, 288-303. [CrossRef] [PubMed]

23. Zhou, C.; Wang, F.; Chen, H.; Li, M.; Qiao, F.; Liu, Z.; Hou, Y.; Wu, C.; Fan, Y.; Liu, L.; et al. Selective antimicrobial activities and action mechanism of micelles self-assembled by cationic oligomeric surfactants. ACS Appl. Mater. Interfaces 2016, 8, 4242-4249. [CrossRef]

24. Ghosh, C.; Manjunath, G.B.; Akkapeddi, P.; Yarlagadda, V.; Hoque, J.; Uppu, D.S.; Konai, M.M.; Haldar, J. Small molecular antibacterial peptoid mimics: The simpler, the better! J. Med. Chem. 2014, 57, 1428-1436. [CrossRef]

25. Davidson, M.P.; Critzer, F.J.; Taylor, T.M. Naturally Occurring Antimicrobials for Minimally Processed Foods. Annu. Rev. Food Sci. Technol. 2013, 4, 163-190. [CrossRef]

26. Yadav, A.N.; Kour, D.; Rana, K.L.; Yadav, N.; Singh, B.; Chauhan, V.S.; Rastegari, A.A.; Hesham, A.E.-L.; Gupta, V.K. New and Future Developments in Microbial Biotechnology and Bioengineering: Microbial Secondary Metabolites Biochemistry and Applications; Gupta, V.K., Pandey, A., Eds.; Elsevier B.V.: Amsterdam, The Netherlands, 2019; Chapter 20, p. 279. [CrossRef]

27. Lobato, C.C.; Ordoñez, M.E.; Queiroz, R.L.; Santos, C.B.R.; Borges, R.S. A comparative study between kojic acid and its methylated derivatives as antioxidant related to maltol and alomaltol. Chem. Data Collect. 2020, 28, 100464. [CrossRef]

28. Hall, R.L.; Oser, B.L. Recent progress in the consideration of flavoring ingredients under the Food Additives Amendment: III. GRAS Substances. Food Technol. 1965, 19, 151-197.

29. Ziklo, N.; Tzafrir, I.; Shulkin, R.; Salama, P. Salicylate UV-Filters in Sunscreen Formulations Compromise the Preservative System Efficacy against Pseudomonas aeruginosa and Burkholderia cepacian. Cosmetics 2020, 7, 63. [CrossRef]

30. Jansen, A.C.; Boucher, C.E.; Coetsee, E.; Kock, J.L.F.; van Wyk, P.W.J.; Swart, H.C.; Bragg, R.R. The influence of Didecyldimethylammonium Chloride on the morphology and elemental composition of Staphylococcus aureus as determined by NanoSAM. SRE 2013, 8, 152-160. [CrossRef]

31. Yoshimatsw, T.; Hiyama, K. Mechanism of the Action of Didecyldimethylammonium chloride (DDAC) against Escherichia coli and Morphological Changes of the Cells. Biocontrol Sci. 2007, 12, 93-99. [CrossRef] [PubMed]

32. Langsrud, S.; Steinhauer, K.; Lüthje, S.; Weber, K.; Goroncy-Bermes, P.; Holck, A.L. Ethylhexylglycerin Impairs Membrane Integrity and Enhances the Lethal Effect of Phenoxyethanol. PLoS ONE 2016, 11, e0165228. [CrossRef]

33. Bendini, A.; Cerretani, L.; Pizzolante, L.; Toschi, T.G.; Guzzo, F.; Ceoldo, S.; Marconi, A.M.; Andreetta, F.; Levi, M. Phenol content related to antioxidant and antimicrobial activities of Passiflora spp. Extracts. Eur. Food Res. Technol. 2006, 223, 102-109. [CrossRef]

34. Zborowskia, K.; Grybosa, R.; Proniewicz, L.M. Vibrational and computational study on maltol (3-hydroxy-2-methyl-4h-pyran-4one) polymorphism. Vib. Spectrosc. 2005, 37, 233-236. [CrossRef]

35. Russell, A.D. Challenge testing: Principles and practice. Int. J. Cosmet. Sci. 2003, 25, 147-153. [CrossRef] [PubMed]

36. Connolly, P.; Bloomfield, S.F.; Denyerl, S.P. The use of impedance for preservative efficacy testing of pharmaceuticals and cosmetic products. J. Appl. Bacteriol. 1994, 76, 68-74. [CrossRef] [PubMed] 
37. Joung, D.-K.; Choi, S.-H.; Kang, O.-H.; Kim, S.-B.; Mun, S.-H.; Seo, Y.-S.; Kang, D.-H.; Gong, R.; Shin, D.-W.; Kim, Y.-C.; et al. Synergistic effects of oxyresveratrol in conjunction with antibiotics against methicillin-resistant Staphylococcus aureus. Mol. Med. Rep. 2015, 12, 663-667. [CrossRef]

38. Wind, C.M.; de Vries, H.J.C.; van Dam, A.P. Determination of in vitro synergy for dual antimicrobial therapy against resistant Neisseria gonorrhoeae using Etest and agar dilution. Int. J. Antimicrob. Agents 2015, 45, 305-308. [CrossRef] 